\title{
Nursing Students' Clinical Practice Experience during the COVID-19 Pandemic: A Qualitative Study
}

\author{
Dian Susmarini $^{1 *}$ (D), Made Sumarwati ${ }^{1} \mathbb{D}$, Fitria Handayani $^{2} \mathbb{D}$, Asep Iskandar $^{1}$ (D) \\ ${ }^{1}$ Department of Nursing, Faculty of Health Science, Universitas Jenderal Soedirman, Purwokerto, Indonesia; ${ }^{2}$ Department of \\ Nursing, Faculty of Medicine, Universitas Diponegoro, Semarang, Indonesia
}

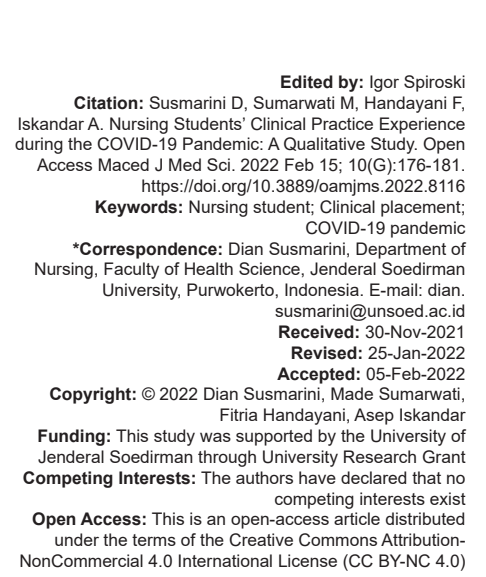

Abstract

BACKGROUND: The COVID-19 pandemic is putting clinical practice in all nursing schools to the challenge. While students should be cautious of infection, they still need to practice in a hospital setting.

AIM: The purpose of this study is to gain insight into students' clinical experiences during the COVID-19 pandemic.

METHODS: This study employed a qualitative methodology and a phenomenological approach. A purposive sampling technique was used to recruit seven clinical nursing students. We conducted semi-structured interviews until the data were saturated. Data were analyzed with thematic analysis to identify and describe the patterns.

RESULTS: Five major themes emerged from students' clinical practice experience during the COVID-19 pandemic: Psychological response, obtained support, inconvenient experience, positive side, and coping

CONCLUSION: The findings suggested that nursing school must address the difficulties students perceive, as clinical practice learning will almost certainly change in the following years due to the epidemic.

\section{Background}

The COVID-19 pandemic has been going on for 2 years since it was first discovered [1]. The impact of the pandemic is not only on health services but on all aspects, including health education. Like other fields of health, nursing has obstacles in the educational process. Most nursing schools closed at the beginning of the pandemic [2]. However, schools should not wait until the epidemic is over. Nursing schools and hospitals are looking for strategies to allow students to have clinical experience and enable them to graduate on time. The world needs more nurses in this pandemic. The learning process must continue in the midst of a pandemic even if nursing students are at risk of infection.

Nurses are at the forefront of treating COVID-19 patients. In some countries, nursing students are required to help treat COVID-19 patients, such as Brazil [3], Spain [4], and Brunei [5]. Theoretically, nursing students should not be considered as employees. Students are still learning to care for patients and need direction on what to do. This pandemic changed this rule because of hospital demands for nurses to treat COVID-19 patients.
There have been many studies investigating nursing student experiences in academia during this pandemic, but research in clinical practice is rare. The field of nursing is of concern because it involves clinical practice. When most people live far from the hospital, nursing students must be present there. A study found that students feel anxious about exercise during a pandemic [6]. Being in clinical practice is a challenge for students in terms of risk of infection, uncertainty, changing learning methods, and shorter duration [3]. Therefore, researchers have been trying to find best practices for nursing education. This study aims to gain deeper insight into students' experiences in clinical placements during this pandemic.

\section{Methods}

This study uses a qualitative research with a phenomenological approach. This method is used to explore phenomena through in-depth interviews. The research was conducted at one of the public 
universities in the Central Java that conducted clinical practice during the pandemic. Several other educational institutions in the region did not get the opportunity to practice, so only one institution was involved in this study. The population was nursing students in the final year who have completed two semesters of clinical placements during this pandemic. Only those who have had completed all the departments are eligible for this study as they have experienced both online and offline learning. Students have passed all departments, including basic nursing, adult nursing, pediatric nursing, maternity nursing, mental health nursing, emergency nursing, nursing management, and community and family nursing.

\section{Procedure}

The research was conducted in AugustSeptember 2021. Researchers chose students who were able to express their experiences so as to facilitate the interview process. The participant recruitment process and interviews were conducted by telephone to avoid contact during the pandemic. Participants received an individual explanation of the study procedures by telephone and agreed to sign the informed consent on the Google form. The interview process is $30-40$ min per participant. Semi-structured interviews were conducted on seven participants and terminated when data reached saturation. Data saturation is the point at which acquiring more data will not add new information [7]. The list of structured questions is as follows:
a. How do you feel about clinical placements during the pandemic?
b. How do you think the pandemic will impact these clinical placements?
c. How was your clinical placement during this pandemic?

\section{Ethical clearance}

This study has passed an ethics test with number 453/EC/KEPK/V/2021, dated May 31, 2021, published by the Ethics Commission of the Faculty of Health Sciences, Jenderal Soedirman University. Ethical considerations include the accuracy of research methods, research procedures, participants' rights, informed consent review, and utilization of research data.

\section{Data analysis}

Data were analyzed using NVIVO series 12 , with verbatim first. A thematic analysis was used to identify and describe the patterns from the gathered data [8]. The categories obtained with NVIVO were then analyzed repeatedly by the research team to obtain themes.

\section{Results}

This study identified five categories: Intrapersonal response, obtained support, inconvenient experience, positive side, and coping. Table 1 shows the identified categories and keyword in every sub-category.

Table 1: Themes and keyword

\begin{tabular}{lll}
\hline Category & Sub Category & Keyword \\
\hline $\begin{array}{l}\text { Intrapersonal } \\
\text { response }\end{array}$ & Psychological & $\begin{array}{l}\text { Fear of infection } \\
\text { Pride (being part of the } \\
\text { pandemic history) }\end{array}$ \\
& Spirituality & $\begin{array}{l}\text { Gratitude } \\
\text { Destiny }\end{array}$ \\
& Perception over COVID & $\begin{array}{l}\text { Punishment } \\
\text { Parental approval }\end{array}$ \\
Obtained & Family support & Checking in \\
support & Friends support & Lack of clinical competencies \\
Inconvenient & Clinical experience & Lack of clinical hours \\
experience & & Frequent changing regulations \\
& & COVID test \\
& Financial burden & Personal protective equipment \\
& & Nutritious food \\
& Self-isolation \\
& COVID related procedures & Tracing \\
& & Regular COVID test \\
Teaching activity \\
Positive side & Technology mastery & Keep the immunity strong \\
Learn more about COVID-19 & Communication skill \\
& Self-care & Time efficient \\
& More creative \\
\hline
\end{tabular}

\section{Intrapersonal response}

Intrapersonal response describes a process within the self-consisting of psychological, spirituality, and perception over COVID. Psychologically, students feel fear, pride, and gratitude over COVID-19.

\section{Psychological response}

Fear of infection was stated by all participants.

"I think the experience of clinical placement during this pandemic was quite worrying because I was more afraid of being infected, and I passed it on to others" (P1)

Pride (being part of the pandemic history)

Two participants felt the pride to be part of the pandemic history

"The interesting thing about the clinical placement in this pandemic is that I can be part of a history of health during this pandemic. This is something that I think rarely happens, or in the future, it may be different in terms of conditions and situations" (P1,2)

\section{Spirituality}

Gratitude: Three participants (P4, 6, and 7) stated the feeling of gratitude for the opportunity of practice during the pandemic. 
"The interesting thing, among them is, well, even with a pandemic like this, but we still have the opportunity to be able to $\mathrm{hmmm}$... practice in the clinic" (P6)

\section{Perception over COVID}

Destiny: Despite being concerned about the possibility of infection, a participant saw this as destiny.

"Worrying is also natural, but anxiety is one of the provisions so that as much as possible we would not get infected. Even if we get infected later, well, it is destiny anyway. The important thing is how to continue to take care of yourself" (P7)

Punishment: This pandemic is seen as a punishment for the human's wrongdoing.

".as a rebuke to what an individual or human has done. It is a human act, so we have to be careful... be careful for what we do and maybe we should pay more attention to safety." (P3)

\section{Obtained supports}

\section{Family's support}

Family's support is mainly in the form of parent's approval for the clinical placement during pandemic with a caution.

\section{Parent's approval}

"The family also supports, in this case, the family also realizes that the child has entered the health sector so that whatever the risk is, it is something that is not so worrying. It is just that there is still a sense of worry and try to take care of yourself" (P1)

"Parents still allow us to do clinical practice... just remind us to be more careful and be more alert" (P2)

\section{Friend's support}

Checking in: More communication is seen among students to make sure; they are healthy.

"We become more concerned... so more concerned about our environment. Hence, in a pandemic situation like this, we are becoming more aware, more concerned, and then more aware of how things are around us. Hence, usually we tell each other things like that, ma'am. If, for example, there is a member of the group or one of the teammates who may be unwell, or something like that, we will care more, ask how they are." (P2)

\section{Inconvenient experience}

\section{Clinical experience}

Lack of clinical competencies (P1-7): All participants stated the lack of clinical competencies.
"The achievement of competence is considered less or less than optimal because it is possible that some skills are not carried out during learning in clinical practice. ...because, during practice we may not find cases or cannot practice skills according to competency targets." (P3)

Lack of clinical hours (P4, 5, 6, and 7): As the regulation of the hospital, clinical duration is reduced.

"Less practice time, right? I think this also reduces students' clinical achievement" (P5)

Frequent changing regulations: As a result of cases fluctuation, nursing school and hospitals change the regulation frequently regarding clinical admission time, COVID-19 procedures, and ward requirements.

"Sometimes when moving from one ward to another, there is usually a shift and room schedule. This shift is sometimes announced the day before, even though if you want to go to the hospital, there are usually tests needed such as rapid and antigen." (P2)

\section{Financial burden}

COVID-19 test (P3 and 5): Another opinion is COVID-19 test that becomes a burden financially.

"...require a COVID test, which of course for students; cost is a problem... because everyone has a different financial level." (P3)

Personal protective equipment (PPE): Even though hospitals provide PPE, students still have to be better prepared by buying more.

".at the beginning of clinical practice during the pandemic, it was also the cost of rapid tests, the cost of buying PPE, etc. So it goes up... so it adds to the financial burden, in my opinion. (P5)

Nutritious food: This is regarded as a way students consume healthier food and store more food for the self-comfort.

"Because we have to maintain our immune system, that is why we have to buy lots of nutritious food and make sure we do not run out of food." (P2)

\section{COVID procedures}

Participants in this study experienced a peak in cases, and some were infected. Therefore, they need to follow the COVID-19 rules that interfere with the training process.

\section{Self-isolation}

"Then, in this pandemic period, in terms of aspects, I think that the shortage is more in skills because of the reduction in hours, the length of practice time is also reduced, especially if someone has to selfisolate so the skills are greatly reduced." (P7) 
Tracing

"For example, a student in my group during a maternity nursing practice became infected. Therefore, all group members must be tracked, so I only practice for a week at the hospital, the remaining weeks I practice at the community health center" (P2)

\section{Positive side}

\section{Technology mastery}

This pandemic allows students to do more of their activities online; therefore, it is necessary to explore information technology in clinical placements.

\section{Teaching activities}

"In the sense of being closer to technology, we are becoming more literate because there are online learning methods, and we are becoming even more proficient in technology" (P2)

\section{Coping}

\section{Self-care}

To survive in this pandemic, students take care of themselves such as keeping good immunity and learning more about COVID-19 prevention.

\section{Keep the immunity strong}

"May be because of the many tasks we have to do while also maintaining immunity. But as much as possible I also try to manage the time well so that there is a break during the break, like that." (P2)

\section{Learn more about COVID-19}

"Here, during this pandemic, I try to take care of myself and also others by always wearing PPE, and I also learn about the transmission of COVID, wash my hands, change clothes immediately, and so on." (P6)

\section{Self-improvement}

In addition to self-care, students try to learn soft skills from this situation.

\section{Communication skills}

"Well, it is more about stringing sentences, then stringing words, sending more messages at the right time, not disturbing personal time, more on ethics in sending messages." (P2)

\section{Time efficient}

"So more value for time, so if friends contact me, then we will not respond too long or if there is a misunderstanding or problem, it must be resolved as soon as possible." (P4)

\section{More creative}

"We strive every day to achieve these targets creatively and innovatively. With creativity, for example, we cannot practice directly, it can be replaced by watching YouTube." (P4)

\section{Discussion}

Several participants expressed that being a witness to the pandemic was an honor. This may be because students feel they have the opportunity to see firsthand the areas directly affected by the pandemic [9]. Even in a study in Nigeria, $79 \%$ of respondents said that they would continue clinical practice amid the pandemic [10]. The opportunity for clinical practice during the pandemic creates gratitude among students because some institutions do not get practice slots in hospitals. Restrictions on the number of students and including practice hours are carried out by the hospital for the safety of students and other health workers. Although proud and grateful to be given the opportunity to practice during the pandemic, the students have feelings of fear and anxiety.

Reactions of fear and worry doing clinical practice during the pandemic were found in all participants. Another study found the same results [9], [11]. There are several causes of fear felt by practice students: Fear of infection, fear of transmitting [11], and uncertainty [9]. This fear is natural because students are in a place with a high risk of transmission. The World Health Organization estimates that 115,500 health workers have died from COVID-19 in the period January 2020-May 2021 [12]

This fear was also felt by the parents of those students, but eventually allowed the students to do clinical practice. The view that getting infected is destiny and that the use of health measures, PPE, and maintaining immunity can prevent COVID helps parents allow their children to practice. However, intense communication is also carried out to control the child's condition. Parental approval and communication [13] are considered as a great support for students. Students' mental health should focus on assisting students in performing their best in clinical practice [14]. Supports from family, friends, teachers, and instructors are significant for students' comfort [11]. According to Levitt, et al., teachers should provide intense caring 
and communication, the proper teaching method, and reduce uncertainty through policy [15].

Support between friends is increasing compared to before the pandemic, although more through online chat platforms. Students check in with each other to ask about the situation, especially when their friends are sick. This pandemic situation has a positive impact on increasing awareness among students. Even in the community, it is advised to check between friends to make sure others are okay during the pandemic due to limited opportunities to meet in person. This suggestion is also supported by a study in Indonesia which states that social relationships with peers, family, and society contribute to the moral strength of adolescents in dealing with the physical and mental consequences of a pandemic [13]

The unpleasant thing about the practice during the pandemic that was felt by all participants was that the achievement of clinical competence was not yet optimal [10], [16]. This is due to the limited practice time in the hospital. Some hospitals regulate practice hours and reduce student numbers for the sake of student and patient safety [5], [17], [18]. Nursing schools are also pulling students from hospitals for fear of getting infected [19]. Students have a list of clinical skills that must be achieved, but not all of them can be done during practice. The thing to do is discuss cases online and watch clinical skills in videos provided by the school. Students also complained about schedule changes and erratic ward relocations, accompanied by different rules in each practice room. Some wards allow or prohibit students from practicing a few days in advance due to new cases in the wards. This requires students to always be ready for rapid changes.

Student conditions such as the need for tracing, COVID tests, and self-isolation interfere with the training process. If the tracing shows that the student is infected, the practice should not be carried out for up to 14 days. The different procedures applied in many wards created an atmosphere of uncertainty in practice. Uncertainty during learning also occurs in an academic setting [9]. In addition, two participants said that COVID tests and the need for more nutritious food added to the financial burden. No previous research has shown the financial burden associated with testing for COVID and a more nutritious diet. Therefore, these findings should be investigated further.

In practice during the pandemic, students showed positive coping with a commitment to selfcare and self-improvement. Students must wear PPE and keep immunity strong. A study in Oman found that nursing students have higher obedience toward COVID prevention [20]. In addition, as one student pointed out, one needs to eat nutritious food, have time to have fun, and avoid excessive stress. One participant suggested that maintaining this immune system also requires more money, thus increasing daily expenses. Awareness of this immune guard signifies vigilance against the transmission of COVID. According to a Turkish study, those whose income is less than their expenses show lower coping behaviors [21].

Practice during a pandemic makes students learn to develop themselves to keep achieving goals with all its limitations. Things that they learned include effective communication [11], using time effectively, and being more creative. Effective communication is associated with limited time to meet so that misunderstandings do not occur. Care in choosing words when speaking through WhatsApp requires observation and practice. Limited meeting time also makes students learn to use the short time to complete tasks effectively so that there is no need to communicate anymore through online platforms. Meanwhile, the creativity done by students is in learning so that they better master clinical skills. An example is a discussion with a friend by looking at clinical procedures on YouTube.

The pandemic, however, gives students a chance to master technology [22]. Technology is used during online counseling and communication due to the lack of face-to-face meetings [6]. Guidance is provided either offline or online meetings. However, during clinical placements, hours are reduced so that discussions other than bedside teaching are conducted online. Online communication through chat platforms that exist today, apart from chatting, is also used to complete group assignments online through real-time such as Google Drive. This situation makes students and clinical instructors master communication technology significantly.

The pandemic situation has both positive and negative sides for students. Positive situations that arise, such as increased mastery of technology, more support from family and friends, creativity, and positive coping, can continue to increase. Meanwhile, the negative side of practice during this pandemic, such as unreachable competencies, fear, and the cost of testing for COVID, requires educational institutions to find ways and solutions. Students' creativity in finding information about clinical skills and cases on the internet is a reasonable basis for using technology in clinical learning. One study proposes the use of telenursing to anticipate reduced clinical placement opportunities [22]. This virtual method needs to be developed to provide a real clinic-like situation.

Good coping shown by students in responding to situations during a pandemic must be maintained. Nursing schools can help them improve their skills through clinical preparation programs. Thus, they will be more confident and ready to treat patients and interact with other health workers. It is suggested that the changes caused by the pandemic will most likely continue for years to come [18]. Therefore, nursing schools must prepare students for clinical placements during the pandemic and face the demands of advanced healthcare. These efforts can be started by modifying teaching methods, paying attention to physical and mental health, providing PPE [11], and increasing soft 
skills [3], [14]. Above all, as nursing students must be professional, nursing schools must help them to have professional characteristics [1], [18]. Once students have these characteristics, they will be better prepared to work in pandemic and post-pandemic situations.

\section{Conclusion}

The themes that emerged in this study described the situation of students practicing during the pandemic. The conditions and changes that occurred during this pandemic provide new insights about the state of the post-pandemic student practice which is expected to remain the same. The emerging themes can be input for educational institutions on policy practices in the coming years, including learning methods to achieve competence, provision of COVID tests, teacher-student interactions, and the support students need during the pandemic. Future research is expected to be able to find appropriate learning methods to accommodate changes in the setting in clinical practice.

\section{References}

1. Shun SC. COVID-19 pandemic: The challenges to the professional identity of nurses and nursing education. J Nurs Res. 2021;29(2):e138. https://doi.org/10.1097/ JNR.0000000000000431

PMid:33661790

2. Agu CF, Stewart J, McFarlane-Stewart N, Rae T. COVID-19 pandemic effects on nursing education: looking through the lens of a developing country. Int Nurs Rev. 2021;68(2):153-8. https:// doi.org/10.1111/inr.12663

PMid:33513283

3. Franzoi MA, Cauduro FL. Participation of nursing students in the Covid-19 pandemic. Cogitare Enferm. 2020;25:e73491.

4. Hernández-Martínez A, Rodríguez-Almagro J, Martínez-Arce A, Romero-Blanco C, García-Iglesias JJ, Gómez-Salgado J. Nursing students' experience and training in healthcare aid during the COVID-19 pandemic in Spain. J Clin Nurs. 2021;00:18. https://doi.org/10.1111/jocn.15706 PMid:33590573

5. Atiqah $\mathrm{A}, \mathrm{Hj} \mathrm{H}$, Aziz A, Abdul-Mumin $\mathrm{KH}$, Rahman $\mathrm{HA}$. Willingness of university nursing students to volunteer during the COVID-19 pandemic in Brunei Darussalam. Belitung Nurs J. 2021;7(4):285-93. https://doi.org/10/33546/bnj.1518

6. Oducado RM, Tuppal C, Estoque H, Sadang J, Superio D, Real DV, et al. Internet use, eHealth literacy and fear of COVID19 among nursing students in the Philippines. Int J Educ Res Innov. 2021;15:487-502. https://doi.org/10.46661/ijeri.5520

7. Lowe A, Norris AC, Farris AJ, Babbage DR. Quantifying thematic saturation in qualitative data analysis. Field Methods. 2018;30(3):191-207.https://doi.org/10.1177/1525822X17749386

8. Snyder H, Engstrom J. The antecedents, forms and consequences of patient involvement: A narrative review of the literature. Int J Nurs Stud. 2016;53:351-78. https://doi. org/10.1016/j.jijnurstu.2015.09.008

PMid:26602069

9. Hussien RM, Elkayal MM, Shahin MA. Emotional intelligence and uncertainty among undergraduate nursing students during the COVID-19 pandemic outbreak: A comparative study. Open Nurs J. 2020;14(1):220-31. https://doi. org/10.2174/1874434602014010220

10. Abazie O, Okwuikpo M, Adetunji A, Nweke C. Coronavirus: Nursing students' knowledge and risk perception of clinical practice during the pandemic. Nurs Midwifery Stud. 2021;10(2):107-13. https://doi.org/10.4103/nms.nms_76_20

11. Ulenaers D, Grosemans J, Schrooten W, Bergs J. Clinica placement experience of nursing students during the Covid19 pandemic: A cross-sectional study. Nurse Educ Today. 2021;99:104746. https://doi.org/10.1016/j.nedt.2021.104746

12. World Health Organization. Health and Care Worker Deaths during COVID-19. Geneva: World Health Organization; 2021. Available from: https://www.who.int/news/item/20-10-2021-health-and-careworker-deaths-during-covid-19 [Last accessed 2022 Jan 24].

13. Rahiem MD, Krauss SE, Ersing R. Perceived consequences of extended social isolation on mental well-being: Narratives from indonesian university students during the covid-19 pandemic. Int J Environ Res Public Health. 2021;18(19):10489. https://doi. org/10.3390/ijerph181910489 PMid:34639788

14. $\mathrm{Xu} \mathrm{B}, \mathrm{Yu}$ J, Li S, Chen L, Lin Z. Factors influencing the coping abilities in clinic nursing students under public health emergency (COVID-19): A cross-sectional study. BMC Nurs. 2021;20(1):1-7. https://doi.org/10.1186/s12912-021-00686-0

15. Levitt $C$, Goulet M, Murphy J, Norman-Eck R, Bhatt A. Nursing education during a pandemic: Perspectives of students and faculty. J Nurs Educ Pract. 2020;11(4):19. https://doi. org/10.5430/jnep.v11n4p19

16. Lona M, Zendrato V, Fernanda V, Hiko D. Impact of Covid19 in nursing education: Literature review. Str J IIm Kesehat. 2021;10(1):577-85. https://doi.org/10.30994/sjik.v10i1.673

17. Godbold R, Whiting L, Adams C, Naidu Y, Pattison N. The experiences of student nurses in a pandemic: A qualitative study. Nurse Educ Pract. 2021;56:103186. https://doi.org/10.1016/j. nepr.2021.103186 PMid:34555786

18. de Carvalho Lira AL, Adamy EK, Teixeira E, da Silva FV. Nursing education: challenges and perspectives in times of the COVID-19 pandemic. Rev Bras Enferm. 2020;73(Suppl 2):e20200683. https://doi.org/10.1590/0034-7167-2020-0683 PMid:33111782

19. Dewart G, Lynn C, Lorraine T, Kristin P. Nursing education in a pandemic: Academic challenges in response to Covid-19. Nurse Educ Today. 2020;92:104471. https://doi.org/10.1016/j. nedt.2020.104471

PMid:32502723

20. Alshdefat A, Natarajan J, Joseph MA. Knowledge, attitude and practice of nursing students towards COVID-19 pandemic in Oman. Int J Nurs Educ. 2021;13(1):23-30. https://doi. org/10.37506/ijone.v13i1.13307

21. Gamze A, Türkan K. Covid-19 perception of senior nursing students and their behaviours regarding coping with stress. Int Arch Nurs Health Care. 2021;7(2):161-9. https://doi. org/10.23937/2469-5823/1510161

22. Hargreaves L, Zickgraf $P$, Paniagua N, Evans TL, Radesi L. COVID-19 pandemic impact on nursing student education: Telenursing with virtual clinical experiences. SAGE Open Nurs. 2021;7:23779608211044618. https://doi. org/10.1177/23779608211044618

PMid:34692998 